\title{
Introduction: Cultural Literacy and Creativity
}

\begin{abstract}
The introductory chapter explains the core concepts of the book: Cultural literacy and creativity. Cultural literacy is defined as a social practice that is inherently dialogic and based on learning and gaining knowledge through emphatic, tolerant, and inclusive interaction. Creativity is seen as stimulating cultural literacy learning through openness and curiosity to test and develop something new or imaginative. The chapter introduces the Cultural Literacy Learning Programme (CLLP) and the research data: 1906 works created by 5-15-year-old children and young people who participated in the program in 2019 and 2020 in Cyprus, Germany, Israel, Lithuania, Spain, Portugal, and the UK. The authors discuss how the data is explored through data-driven content analysis and self-reflexive and collaborative interpretation.
\end{abstract}

Keywords Cultural literacy - Creativity - Artifact - Content analysis · Self-reflexive interpretation

\section{Focuses, Premises, and Objectives}

Literacy is a core skill for learning and development. It enables communication and dialogue within a community and allows people to engage in society. Since the 1990s, scholars and educators have approached literacy

(C) The Author(s) 2022

T. Lähdesmäki et al., Learning Cultural Literacy through

Creative Practices in Schools, https://doi.org/10.1007/978-3-030-89236-4_1 
as more than the ability to read and write language-based texts. The concept of multiliteracies, introduced by the New London Group in the mid-1990s and since then broadly utilized in education policy discourses and national curricula, stems from a wider understanding of text by emphasizing multimodality in meaning-making: Language-based communication intertwines with visual, auditive, corporal, gestural, and spatial patterns of meaning. The need to rethink and redefine literacy also reflects the diversification of contemporary societies and the rapid development of information technologies during the past two or three decades. For the New London Group, the multiplicity of new communication channels and increased cultural and linguistic diversity demanded a new approach to literacy pedagogy (Cazden et al. 1996). Since the introduction of the concept of multiliteracies, the social reality in different parts of the world has become even more culturally plural or "super-diversified," as Vertovec (2007) has described this change. In super-diversified societies, diversity itself is complex, multidimensional, fluid (Vertovec 2007; Blommaert and Rampton 2011), and characterized by the intersection of different social locations and positions related to culture, ethnicity, nationality, religion, language, gender, sexuality, and ability.

Since societies are diversifying, creating new challenges to communication, we need to approach the concept of literacy in a broader context. In this book, we explore positive responses to this context: The idea of difference and the ability to encounter, communicate, learn, and live together through empathic, tolerant, and inclusive interaction with others who may be different from us. We show how the concept of cultural literacy as a tolerant, empathic, and inclusive approach to differences can be taught and learned in schools through creative practices. Our focus is on meaning-making in children and young people's visual and multimodal artifacts created in schools as an outcome of tasks aiming to foster cultural literacy learning. This interdisciplinary exploration is located at the intersection of different approaches to children's creativity, art, and learning: We draw on research in cultural studies, communication studies, art education, and educational sciences.

Our approach to children and young people's creative expression of cultural literacy relies on two intertwined premises about living together as cultural beings. First, in our view, creativity and imagination are essential features of humanity that particularly characterize children's way of grasping the world. A considerable body of literature discusses the nature of children's creativity and visual expression. While some scholars have 
explained this as either children's attempts to draw what they know or what they see, recent studies give a more nuanced view of children's creative processes in image-making and its various possible functions. For Deguara (2015), drawing can function as a constructor of children's identity, communicator of the child's self, processor of children's knowledge, and a play process. In this book, we approach image-making and other artistic practices as modes of expression that allow children to develop their imagination, personality, dialogic relationship to others, and emotional responses in a creative way (see Lähdesmäki and Koistinen 2021); these practices help children to deal with and shape their mental images and understanding of the world in a constructive process of thinking in action (see Cox 2005; Deguara 2015). For many children, image-making and artistic creation are acts that connect their inner thoughts, emotions, and imaginings to the external world by intertwining their events and experiences that are personal to them with real-life episodes (Jolley 2010; Wright 2010; Deguara 2015). These entanglements of the inner and external worlds are impacted by the culture of the environment in which children create their images as well as by the imageries of contemporary popular culture (Toku 2001; Jolley 2010; Wright 2010). Image-making and nonlanguage-based artistic practices enable children to process what can be difficult to express in words through oral or written communication (Clark 2005; Deguara 2015). As an instrument, it is, thus, suitable for the teaching and learning of abstract topics such as cultural literacy.

The second premise of the book stems from an increasing need for respectful cultural encounter, mutual understanding, and constructive dialogue in today's super-diversified, but polarized, societies (see Lähdesmäki et al. 2020). While many societies have become increasingly diverse social spaces where people can simultaneously identify with multiple different cultural and social groups, monoculturalist views and cultural purism have struck back. Western societies have faced a rise in populist, nationalist, and extremist movements that have incited xenophobic, anti-immigration, misogynist, racist, anti-Semitic, and Islamophobic political attitudes and actions. Western societies have commonly recognized cultural pluralization as a richness that, however, entails diverse challenges when the cultural encounter is not based on mutual respect and an interest in understanding differences. Cultural literacy learning is a key to advance tolerant, empathetic, and inclusive attitudes toward diversity. 
For our book, we have four core objectives. First, we seek to strengthen a sociocultural approach to children's expression moving away from developmental and cognitive approaches that have long dominated the research on children's art to understanding children as active cultural agents. Therefore, we do not take a psychological approach (using art to discover the child's inner conflicts), a behavioral approach (using art to examine the child's thinking processes), a developmental approach (exploring the child's visual expression at a particular age level), or an art pedagogical approach (helping children develop visual expression) (Nikoltsos 2001). In the 2000s, scholars (e.g., Anning 2003; Ivashkevich 2009; Atkinson 2009; Coates and Coates 2011; Deguara 2015) have noted a paradigm shift toward researching children's art as a process of communication influenced by various sociocultural contexts. This research has shown how children are influenced by the culture(s) and societies surrounding them and how these influences can be perceived from their visual expression. Toku $(2001,46)$ notes how the influence of culture and technology emerges in children's drawings when they start primary school. While children and young people-as all people-feel the impact of their social and cultural contexts, they are not only passive receivers but also active creators of culture. The recent participatory approach to children's art and culture has emphasized children as "social beings who are able, competent agents and active constructors of their knowledge and understanding" (Deguara 2015, 12) and agents of their own learning, "actively defining reality, rather than passively reflecting a 'given reality" (Cox 2005, 12) in their creative practices. Our research for this book is grounded in a contextual and sociocultural approach to children's visual creation, seeing it as a valuable contribution to culture and cultural heritage (Venäläinen 2019).

Second, we seek to determine the potential and limitations of children's creations as research material. Some of these limitations stem from the power relations involved whenever adults research children. We thus critically explore the setting in which the children produced our research material, and the position of the (adult) researcher, as an interpreter of children's visual expression and as a knowledge producer based on the analysis of such data.

Third, we apply theoretical discussions on multimodality to explore children and young people's creative practices. We follow Kress's notion of multimodality as a "normal state of human communication" (Kress $2010,1)$ that is based on a "multiplicity of ways in which children make 
meaning, and the multiplicity of modes, means, and materials which they employ in doing so" (Kress 1997, 96). In our research, we emphasize how different modes in meaning-making interact and impact on each other in a multimodal synthesis (Jewitt 2008; Walsh 2009). Due to this interaction, all meaning-making can be perceived as multimodal (Cazden et al. 1996).

Fourth, we seek to explore the role of dialogue and creativity in cultural literacy learning and to share new knowledge about how, through dialogic creative processes, children and young people can construct and deepen their understanding of a contemporary world filled with difficult challenges such as exclusion, intolerance, and climate change.

\section{Concepts: Cultural Literacy and Creativity}

The key concept of our research, cultural literacy, is a social practice that is inherently dialogic and based on learning and gaining knowledge through empathic, tolerant, and inclusive interaction. It has been defined as a process of engaging with cultures and a cocreation and expression of cultural identities and values (Maine et al. 2019; Maine and Vrikki 2021). Cultural literacy as such is not a new concept: It has been discussed in academia since the end of the 1980s. The first scholars (e.g., Hirsch 1988, 1989; Hirsch et al. 1993, 2002) of cultural literacy often perceived it narrowly, as knowledge gained through the exploration of cultural products, such as literature and art, and learning canonical cultural and historical facts and narratives. Hirsch (1989), who utilized the concept to argue what students need to fully engage in contemporary society, even lists 5000 "essential names, phrases, dates and concepts" that "every American needs to know," as the cover of his book claims.

The idea of becoming culturally literate by learning selected facts and features of one's own and/or others' culture, history, and heritage has serious limitations. First, it does not recognize culture within a society as an inherently plural, constantly transforming, and fluid social construction based on interaction between diverse people (Otten 2003; Abdallah-Pretceille 2006). Second, the emphasis on factual knowledge of culture, history, and heritage as a key element for cultural encounters may direct people to perceive others as stable representatives of their culture or community. This may lead to cultural stereotyping, making it more difficult to see people as individuals, and even bring about prejudices (Abdallah-Pretceille 2006; Portera 2008). Third, learning facts and features is not cocreation of knowledge: It does not encourage 
learning with or from others who may be different from us. As Messelink and ten Thije $(2012,81)$ note: "The ability to gain knowledge in interaction allows individuals to search for similarities and successfully operate in intercultural (...) contexts, regardless of the cultural backgrounds present." Cultural literacy teachers should seek to promote this tolerant, empathic, and inclusive attitude in social interaction and gaining knowledge with others (Maine et al. 2019).

The concept of creativity is embedded in our approach to cultural literacy. In our view, cultural literacy is learned in a process that allows new ideas and views to emerge, as well as knowledge of differences and similarities, one's own and others' cultural values, and how to encounter, interact, and live together with others. For us, cultural literacy learning is about dialogic cocreation of (or attempts to cocreate) knowledge that can be stimulated by concrete creative practices, such as making an artwork together.

In our approach, creativity, the act of creating, and its outcome, creation, are linked but not equivalent concepts. Dictionaries often define creativity as an individual's ability. It is seen for instance: “The ability to produce original and unusual ideas, or to make something new or imaginative" (Cambridge Academic Content Dictionary 2020) or "the faculty of being creative; ability or power to create" (Oxford English Dictionary 2020). In scholarly literature, the concept has been discussed in a more nuanced manner, emphasizing the complexity of its connotations in different historical periods and in scholarly contexts ranging from aesthetics to philosophy and from psychology to logic, to mention just a few (Pope 2005). The scholars have often concluded that creativity involves the production of novel, useful, or valuable ideas and/or products (Mumford et al. 2002; Mumford 2003; Pope 2005). These views home in on the act of creating. Taking this act as a point of departure for creativity, Mumford et al. (2002) have listed two sets of processes that are involved in creative work: Activities leading to idea generation (ideation) and activities needed to implement ideas (implementation). More recent scholars have criticized the views that equate creativity with creative work and its outcome. This "dynamic definition of creativity" (Corazza 2016; Walia 2019) focuses on ongoing processes in which individuals seek to produce novel and useful ideas or products but may not always succeed. Hence, Corazza $(2016,265)$ has claimed that "the dynamic interplay between inconclusiveness and achievement must be subsumed by the definition of creativity." Walia $(2019,239)$ continues this idea by noting how 
"creation can be judged only when it has concluded, whereas creativity is active throughout the process and may not even end after having led to creation."

Many adults consider children's art as an example of fascinating self-expression and genuine and spontaneous creativity uninfluenced by cultural norms (Nikoltsos 2001). This imagined genuineness and spontaneousness has found its way into discourses of modern art. Since the beginning of the twentieth century, various artists and artistic groups have been inspired by children's visual expression and admired its creativity (Fineberg 1997). In this book, we acknowledge the creative ability of all people, including children, and understand children's visual and multimodal expression as a way to process, seek, and possibly find novel and useful ideas and outcomes. We do not seek to evaluate the creativity of the children's visual and multimodal artifacts that form the core of our data. For us, creativity is not a feature of a person or a product but a dynamic process that stimulates cultural literacy learning through curiosity and openness to something new or imaginative. Artistic creation provides children and young people an arena to practice creativity, meaning-making, and "engage their minds, hearts and bodies" (Wright 2010,2). This engagement itself may be the new outcome. Indeed, various researchers have connected creativity and empathy, to emphasize that art can evoke empathetic responses and understanding of other people's points of view (Lähdesmäki and Koistinen 2021).

\section{The Cultural Literacy Learning Programme, Data and Methods}

As a response to the increasing need for respectful cultural encounters, mutual understanding, and constructive dialogue in today's superdiversified societies, the DIalogue and Argumentation for cultural Literacy Learning in Schools (DIALLS) project developed a Cultural Literacy Learning Programme (CLLP), that was implemented in over 250 classes in Cyprus, Germany, Israel, Lithuania, Spain, Portugal, and the UK in the school year 2019-2020. The program was built by an international group of scholars and teachers and it was aimed at three age groups: students aged 5-6, 8-9, and 14-15. In the implementation of the program, the age span in the groups was a year or two wider in some classes. The program and its pedagogy was based on the concept of cultural literacy defined above: Its builders saw dialogue, argumentation, and interactive 
creative practices as tools for encountering differences, expressing one's own cultural features and values, and learning cultural literacy. In each age group, the CLLP included 15 lessons addressing different themes, ranging from one's cultural attachments to being part of a community and engaging more broadly in society. These themes fell into four groups: Living together (explored by talking about celebrating diversity, solidarity, equality, human rights, democracy, and globalization); social responsibility (focusing on social and civic competences, sustainable development, and active participation); belonging (discussion on home); and the core attitudes for cultural literacy learning (tolerance, empathy, and inclusion). These themes were selected for the CLLP through a clustering exercise of a broad array of concepts and terms highlighted in scholarly literature and education policy documents on cultural literacy and intercultural dialogue (see DIALLS 2018; Lähdesmäki et al. 2020).

The lessons in the CLLP were based on classroom and small group discussions that were stimulated by wordless picture books and films. These books and films had been selected by the project researchers in an attempt to promote the tolerant, empathic, and inclusive encounter of differences and to reflect multicultural, multiethnic, and multilingual social landscape of places, people, and ways of living in Europe and its neighboring regions. Using the books and films in the CLLP enabled "an exploration of the critical and creative thinking processes involved in meaning-making, which is viewed as a dialogic process between readers together and between text and readers" (Maine 2015, 5). Moreover, each lesson in the CLLP included a creative task in which the students were encouraged to explore with visual or multimodal means the ideas developed during classroom and small group discussions, and to explain the content of their creation in a caption.

The learning process in the CLLP was based on multimodal communication in which one mode of communication became interpreted and explored through another. The wordless picture books and films were given meaning through words in oral classroom and small group discussions. The students then explored these meanings through creating (mostly) visual artifacts (which often included written text), for which the students (or their teachers as mediators of the students' voice within the youngest age group) wrote a brief separate explanation, a caption. These artifacts and their captions form the core of our data.

The intertwinement of visual and linguistic modes in our data reflects the central feature of children's creative practices: They are typically based 
on the interplay of two or more semiotic resources (Deguara 2015,4). Particularly in young children's creative practices, visual and oral modes may be difficult to distinguish. As Kinnunen (2015) notes, drawing can be perceived as a kind of dialogue between the marks made on paper and orally narrated thoughts. Some scholars (Siim 2019) have emphasized that children's visual creations cannot be interpreted outside the narrative context and explanation of the artifacts given by the children themselves. We analyze our data based on our understanding that children's creative practices are multimodal. The captions in our data function as a key to the meanings that the children themselves have affixed to their artifacts. In interpreting them, our aim is not to trace the children's thoughts: We believe this is impossible. Following common communication theories, we interpret the data based on "decoding" the signs which the students have "coded" to the artifacts within the various contexts in with they participated in the CLLP (see Rose 2001, 16). This decoding can, however, only occur between us as interpreters and the artifacts as a complex sign.

The lesson plans in the CLLP represent the pedagogical ideal for cultural literacy learning. Respectively, its implementation represents the pedagogical reality, in which the aims and ideals of cultural literacy learning were put into practice in various social and cultural contexts that differ between countries, regions, schools, and classes. The teachers received at least 18 hours of face-to-face professional development on the core ideas of the CLLP. We expected teachers would need 30 hours of working time to prepare and reflect on the lessons. The teachers were encouraged to creatively implement the lesson plans in their classes. Some of them applied the lesson plans more freely, while others closely followed the guidelines. The CLLP pedagogy was based on dialogic teaching emphasizing the co-construction of meanings among students and between them and their teachers: The teachers modeled how to engage democratically in the dialogue (Maine and Čermáková 2021). As in all teaching and learning, this pedagogy included distinct roles for teachers and learners. In the CLLP, the teachers were expected to model the discussion on the themes in the lesson plans and give students instructions for the tasks; the students were expected to participate in the discussions and follow the instructions. The implementation of the CLLP was, thus, intertwined with various issues of power that impacted on what was expressed, how, and why in the artifacts. 
Various scholars have explored the impact of school on children's communication and creative expression. These studies argue that the school context effectively unifies the children's cultural and communicative resources by moving them from being communicative agents of their own worlds alone to also become communicative agents of their society and culture (Kress 1997, 2000; Deguara 2015). The school context-including teachers, peers, classroom practices, and curriculaeither explicitly or implicitly emphasizes certain values, perceptions, and expectations that influence children's visual expression (Einarsdottir et al. 2009; Deguara 2015). Some scholars (Fargas-Malet et al. 2010) have seen this "acculturation to school" as the main shortcoming of research utilizing children's drawings as data: Children may create images that they think will please the teacher or researcher.

Our data includes hundreds of artifacts, mainly multicolored drawings but also a small number of collages, three-dimensional sculptures, short films, and photographs of roleplaying. Most of the artifacts were created individually, but many were made in small groups of 3-6 students, and some by the whole class connecting individually created pieces as a collage. When counting these individual pieces as separate works, the number of artifacts in our data increases to 1906 (Table 1.1). The CLLP teachers photographed the artifacts and sent the photographs and captions to the researchers. The teachers also completed a brief survey including some background information indicating the country, students' ages and genders within the groups, and teachers' description of the progress of the lesson, particularly if some changes to the lesson plan were made. These forms are included in our data. The spread of the COVID-19 pandemic in spring 2020 impacted on the implementation of

Table 1.1 Quantity of individual creative works per country in the CLLP

\begin{tabular}{|c|c|c|c|c|c|c|c|}
\hline & Cyprus & Germany & Israel & Lithuania & Portugal & Spain & $U K$ \\
\hline age $5-6$ & 265 & 9 & 222 & 16 & 199 & 8 & 149 \\
\hline age $8-9$ & 134 & 48 & 93 & 36 & 97 & 18 & 94 \\
\hline age $14-15$ & 0 & 103 & 117 & 90 & 97 & 48 & 2 \\
\hline $\begin{array}{l}\text { COVID-19 works } \\
\text { (all age groups) }\end{array}$ & 25 & 0 & 0 & 23 & 13 & 0 & 0 \\
\hline country total & 424 & 160 & 432 & 165 & 406 & 74 & 245 \\
\hline \multicolumn{8}{|c|}{ Total number of individual creative works: 1906} \\
\hline
\end{tabular}


the CLLP and thus our data collection. Due to the exceptional conditions, not all teachers were able to implement each lesson. Some of our data was created during lockdown when students were learning at home. In this book, some artifacts arising from the subthemes of democracy, globalization, and active participation are not analyzed separately but within the broader themes of living together and social responsibility. Due to the exceptional conditions caused by the pandemic, the CLLP was extended in some countries with an additional lesson in which the students reflected on how COVID-19 had impacted on their social environment and explored ways of practicing empathy, tolerance, and inclusiveness in pandemic conditions.

Our research is based on data-driven content analysis utilizing both qualitative categorizing of the data and quantification of its core features and visual elements (see Rose 2001) and a self-reflexive and collaborative interpretation of what the artifacts mean within their context in the lesson. By self-reflexive interpretation, we mean acknowledging our position as researchers and considering our cultural and social contexts, from which we look at and interpret images (Rose 2001, 15-16; Passerini 2018). Besides, our interpretations have been formed in close collaboration, open dialogue, and sharing of views within our team during the research process.

After this introductory chapter, we proceed to the core theoretical aspects of our analysis. We start by exploring a sociocultural approach to the research on children's visual expression, including the issue of power. Next, we move to multimodality as a way in which students make meanings in our data. The subsequent four chapters each focus on different thematic aspects of cultural literacy learning: Attitudes of tolerance, empathy, and inclusion; living together; social responsibility; belonging; and practicing tolerance, empathy, and inclusion during the pandemic. We start these chapters with a critical discussion of their themes and core concepts - and, in the last chapter, an overview of the pandemic conditions-followed by the data-driven content analysis and interpretation of meaning-making around the themes in the artifacts. When the data allows it, we also compare how the different themes are dealt with in different countries and age groups. To avoid methodological nationalism (creating artificial national categories), we do not systematically pinpoint the home country of students unless we consider this information relevant to the discussion. In our analysis, we also pay attention to how the 
artifacts are influenced by global popular culture and imageries of children's culture that circulate symbols and images from cartoons, films, storybooks, games, or digital environments (see Toku 2001, 52; Coates and Coates 2011; Deguara 2015,83). We end with a chapter summarizing our core results and showing how they expand the understanding of children's creative and multimodal meaning-making processes. In the concluding chapter, we suggest avenues for future research and ways to improve cultural literacy learning through creative practices.

\section{REFERENCES}

Abdallah-Pretceille, M. 2006. "Interculturalism as a Paradigm to Think About Diversity." Journal of Intercultural Education 17 (5): 457-483.

Anning, A. 2003. "Pathways to the Graphicacy Club: The Crossroad of Home and Pre-school." Journal of Early Childhood Literacy 3 (5): 5-35.

Atkinson, D. 2009. "How Children Use Drawing." In Readings in Primary Art Education, edited by S. Hearne, S. Cox, and R. Watts, 139-152. Bristol: Intellect Books.

Blommaert, J., and B. Rampton. 2011. "Language and Superdiversity." Diversities 13 (2): 1-21.

Cambridge Academic Content Dictionary. 2020. Cambridge: Cambridge University Press. https://dictionary.cambridge.org/dictionary/english/creativity.

Cazden, C., B. Cope, F. Fairclough, J. Gee, M. Kalantzis, J. Cook, G. Kress, A. Luke, C. Luke, S. Michaels, and M. Nakata. 1996. "A Pedagogy of Multiliteracies: Designing Social Futures." Harvard Educational Review 66 (1): 60-92.

Clark, A. 2005. "Listening to and Involving Young Children: A Review of Research and Practice." Early Child Development and Care 175 (6): 489-505.

Coates, E., and A. Coates. 2011. "The Subjects and Meanings of Young Children's Drawings." In Exploring Children's Creative Narratives, edited by D. Faulkner and E. Coates, 86-110. Oxon: Routledge.

Cox, S. 2005. "Intention and Meaning in Young Children's Drawing." International Journal of Art \& Design Education 24 (2): 115-125.

Corazza, G. E. 2016. "Potential Originality and Effectiveness: The Dynamic Definition of Creativity." Creativity Research Journal 28 (3): 258-267.

Deguara, J. 2015. "Meaning-making in Young Children's Drawings." PhD diss., University of Sheffield, UK.

DIALLS. 2018. "Cultural Analysis Framework." https://dialls2020.eu/wp-con tent/uploads /2019/09/resubmitted-cultural-analysis-framework-with-covers heet-.pdf. 
Einarsdottir, J., S. Dockett, and B. Perry. 2009. "Making Meaning: Children's Perspectives Expressed Through Drawings." Early Child Development and Care 179 (2): 217-232.

Fargas-Malet, M., D. McSherry, E. Larkin, and C. Robinson. 2010. "Research with Children: Methodological Issues and Innovative Techniques." Journal of Early Childhood Research 8 (2): 175-192.

Fineberg, J. 1997. The Innocent Eye: Children's Art and the Modern Artist. Princeton: Princeton University Press.

Hirsch, E. D. 1988. Cultural Literacy: What Every American Needs to Know. New York: Vintage Books.

Hirsch, E. D. 1989. A First Dictionary for Cultural Literacy: What Our Children Need to Know. New York: Houghton Mifflin Harcourt.

Hirsch, E. D., J. F. Kett, and J. Trefil. 1993. The Dictionary of Cultural Literacy. What Every American Needs to Know, 2nd ed. New York: Houghton Mifflin Company.

Hirsch, E. D., J. F. Kett, and J. Trefil. 2002. The New Dictionary of Cultural Literacy: What Every American Needs to Know, 3rd ed. New York: Houghton Mifflin Company.

Ivashkevich, O. 2009. "Children's Drawing as a Sociocultural Practice: Remaking Gender and Popular Culture." Studies in Art Education: A Journal of Issues and Research 51 (1): 50-63.

Jewitt, C. 2008. "Multimodality and Literacy in School Classrooms." Review or Research in Education 32: 241-267.

Jolley, R. P. 2010. Children and Pictures: Drawing and Understanding. Hoboken, US: Wiley.

Kinnunen, S. 2015. "How Are You? The Narrative In-Between Spaces in Young Children's Daily Lives." PhD diss., University of Oulu, Finland. http://jul tika.oulu.fi/files/isbn9789526210285.pdf.

Kress, G. 1997. Before Writing: Rethinking the Paths to Literacy. London: Routledge.

Kress, G. 2000. "Design and Transformation: New Theories of Meaning." In Multiliteracies: Literacy Learning and the Design of Social Futures, edited by B. Cope and M. Kalantzis, 153-161. London: Routledge.

Kress, G. 2010. Multimodality: A Social Semiotic Approach to Contemporary Communication. Oxon: Routledge.

Lähdesmäki, T., A.-K. Koistinen, and S. C. Ylönen. 2020. Intercultural Dialogue in the European Education Policies: A Conceptual Approach. New York: Palgrave Macmillan.

Lähdesmäki, T., and A.-K. Koistinen. 2021. "Explorations of Linkages Between Intercultural Dialogue, Art, and Empathy." In Dialogue for Intercultural Understanding: Placing Cultural Literacy at the Heart of Learning, edited by F. Maine and M. Vrikki. Cham: Springer. 
Maine, F. 2015. Dialogic Readers. Children Talking and Thinking Together About Visual Texts. London: Routledge.

Maine, F., and A. Čermáková. 2021. "Using Linguistic Ethnography as a Tool to Analyse Dialogic Teaching in Upper Primary Classrooms." Learning, Culture and Social Interaction. https://doi.org/10.1016/j.lcsi.2021.100500.

Maine, F., V. Cook, and T. Lähdesmäki. 2019. "Reconceptualizing Cultural Literacy as a Dialogic Practice." London Review of Education 17 (3): 382-391.

Maine, F., and M. Vrikki. 2021. "An Introduction to Dialogue for Intercultural Understanding: Placing Cultural Literacy at the Heart of learning." In Dialogue for Intercultural Understanding: Placing Cultural Literacy at the Heart of Learning, edited by F. Maine and M. Vrikki. Berlin: Springer.

Messelink, H. E., and J. D. ten Thije. 2012. "Unity in Super-Diversity: European Capacity and Intercultural Inquisitiveness of the Erasmus Generation 2.0." Dutch Journal of Applied Linguistics 1 (1): 80-101.

Mumford, M. D. 2003. "Where Have We Been, Where Are We Going? Taking Stock in Creativity Research." Creativity Research Journal 15: 107-120.

Mumford, D. M., G. M. Scott, B. Gaddis, and J. M. Strange. 2002. "Leading Creative People: Orchestrating Expertise and Relationships." The Leadership Quarterly 13: 705-750.

Nikoltsos, C. 2001. “Researching Children’s Art: Systematic Observations of the Artistic Skills of Young Children. Educational Resources Information Center, the US." https://files.eric.ed.gov/fulltext/ED449899.pdf.

Otten, H. 2003. "Intercultural Learning and Diversity in Higher Education." Journal of Studies in International Education 7 (1): 12-26.

Oxford English Dictionary. 2020. Oxford: Oxford University Press. https:// www.oed.com/view/Entry/44075? redirectedFrom=creativity\#eid.

Passerini, L. 2018. Conversations on Visual Memory. Florence: European University Institute.

Pope, R. 2005. Creativity. Theory, History, Practice. London: Routledge.

Portera, A. 2008. "Intercultural Education in Europe: Epistemological and Semantic Aspects." Intercultural Education 19 (6): 481-491.

Rose, G. 2001. Visual Methodologies. An Introduction to the Interpretation of Visual Materials. London: Sage.

Siim, P. M. 2019. "Drawing and Storycrafting with Estonian Children: Sharing Experiences of Mobility." In Challenges and Solutions in Ethnographic Research: Ethnography with a Twist, edited by T. Lähdesmäki, E. KoskinenKoivisto, V. L. A. Ceginskas, and A.-K. Koistinen, 84-99. London: Routledge.

Toku, M. 2001. "Cross-cultural Analysis of Artistic Development: Drawing by Japanese and U.S. Children." Visual Arts Research 27 (1): 46-59.

Venäläinen, P. 2019. "Katse lasten ja nuorten taiteeseen.” In Jälkikuvia, kuvan jälkiä, edited by P. Venäläinen, J. Lindholm, S. Kairavuori, T. Pusa, and S. Ylönen, 9-18. Helsinki: Nuorisotutkimuksen verkosto. 
Vertovec, S. 2007. New Complexities of Cohesion in Britain: Super-diversity, Transnationalism and Civil-integration. Wetherby: Communities and Local Government Publications.

Walia, C. 2019. "A Dynamic Definition of Creativity." Creativity Research Journal 31 (3): 237-247.

Walsh, M. 2009. "Pedagogic Potentials of Multimodal Literacy." In Handbook of Research on New Media Literacy at the K-12 Level: Issues and Challenges, edited by L. T. W. Hin and R. Subramaniam, 32-47. Hershey, US: IGI Global.

Wright, S. 2010. Understanding Creativity in Early Childhood: Meaning-Making and Children's Drawings. London: Sage.

Open Access This chapter is licensed under the terms of the Creative Commons Attribution 4.0 International License (http://creativecommons.org/licenses/ by $/ 4.0 /)$, which permits use, sharing, adaptation, distribution and reproduction in any medium or format, as long as you give appropriate credit to the original author(s) and the source, provide a link to the Creative Commons license and indicate if changes were made.

The images or other third party material in this chapter are included in the chapter's Creative Commons license, unless indicated otherwise in a credit line to the material. If material is not included in the chapter's Creative Commons license and your intended use is not permitted by statutory regulation or exceeds the permitted use, you will need to obtain permission directly from the copyright holder.

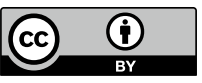

